\section{Prehistoric pigment characterisation of the Abri Pataud rock-shelter (Dordogne, France)}

\author{
Matthieu Lebon,, ${ }^{1,2}$ Lucile Beck, ${ }^{1}$ \\ Sylvain Grégoire, ${ }^{1}$ Laurent Chiotti, ${ }^{2}$ \\ Roland Nespoulet, ${ }^{2}$ Michel Menu, ${ }^{1}$ \\ Patrick Paillet ${ }^{2}$
}

'UMR171 CNRS, Centre de Recherche et de Restauration des Musées de France C2RMF, Palais du Louvre, Paris; 2UMR 7194 CNRS, Département de Préhistoire, Muséum National d'Histoire Naturelle, Paris, France

\section{Abstract}

Iron oxide pigments found in archaeological context constitute an important source of information for the understanding of cultural and subsistence activities of ancient human cultures. In order to complete archaeological contextual information, many analytical methods have been applied to characterise pigments and to provide further information on this material (e.g. supplies, selections, mechanical or physical transformations of raw material, use and application processes). Several studies have demonstrated that the elemental composition of iron oxide pigments can be used to discriminate between several geological provenances. In this study, non-destructive micro-particle induced Xray emission analysis was applied in order to distinguish different kinds of reddish pigments from the prehistoric site of Abri Pataud, more especially from the Layer 2 attributed to Final Gravettian period (22,000 BP). By using an external beam, this technique required no sampling, and enabled us to perform localised analyses directly on raw material, on ochre residues applied on artefacts or on fragments of the wall of this rock-shelter. The results obtained by this technique demonstrate that the pigments covering the decorated fragments of the rock-shelter wall, found during the excavation of the Layer 2, have elemental compositions similar to the composition of a raw pigment found in the same layer. These results suggest that the shelter was decorated during the Final Gravettian period and thus provide new insights for the understanding of the archaeological context of this occupation layer.

\section{Introduction}

Iron-rich minerals have been extensively used in prehistoric period as pigment or for other properties (e.g. abrasive and drying properties). According to archaeological contexts, the use of pigment has been interpreted as the result of cultural behaviours (rock art, funeral practices), or practical uses (polishing, preparation of adhesives) (Lombard, 2007; Mariotti et al., 2009). This material plays thus an important role to reconstruct symbolic and subsistence components of ancient human cultures. In order to complete archaeological contextual information, many analytical methods have been applied to iron-rich mineral to characterise functional tasks including pigment supplies and selections, mechanical or physical transformations of raw material (e.g. either by grinding or heating), and their use (D'Errico et al., 2010; Menu, 2009; Vignaud et al., 2006).

Techniques such as transmission electron microscopy with electron diffraction (Pomiès et al., 1999; Chalmin et al., 2004), scanning electron microscopy combined with energy dispersion spectroscopy (Darchuk et al., 2010), Xray diffraction (Nel et al., 2010), Raman and infrared spectroscopies (Darchuk et al., 2010; Bikiaris et al., 2000; Ramos et al., 2008; Smith et al., 1999) have been used to determine specific iron mineral phases. These methods can also provide information on other minerals associated with these iron oxides, as well as related to the mineralogical composition of the geological source (Nel et al., 2010), or artificially added as extender by human during pigment preparation to enhance specific properties (Clottes et al., 1990). Various elemental analysis methods were also used to characterise rich iron oxide pigments and artefacts. Suitable techniques including X-ray fluorescence (XRF) (Ramos et al., 2008; PopelkaFilcoff et al., 2007), neutron activation analysis (Popelka-Filcoff et al., 2007), inductively coupled plasma mass spectrometry (ICP-MS) (Green and Watling, 2007) or particle-induced X-ray emission spectroscopy (PIXE) (Erlandson et al., 1999; Beck et al., 2011). Some of these studies suggested that the elemental composition of ochre and haematite can provide characteristic chemical proxies of particular geological sources, and can be used for provenance establishment purpose to differentiate geological locations one another. For ICP-MS analysis, laser ablation was used to perform micro-sampling on small area ( $\sim 50$ $\mu \mathrm{m})$ (Green and Watling, 2007). But in most cases, these studies were focused on geological provenances and no specific precautions were thus taken into account for sampling geological materials that were crushed and ground to fine powder prior to analyses (Nel et al., 2010; Popelka-Filcoff et al., 2007; Erlandson et al., 1999). Such methods can not be applied to valuable archaeological artefacts which need the use of non-destructive analytical techniques. However, some of the elemental analy-
Correspondence: Matthieu Lebon, UMR171 CNRS, Centre de Recherche et de Restauration des Musées de France - C2RMF, Palais du Louvre, Porte des Lions, 14 quai François Mitterrand, 75001 Paris.

Tel. +33.01.5543.2711 - Fax: +33.01.4331.2279.

E-mail: lebon@mnhn.fr

Key words: pigment characterisation, Abri Pataud rock-shelter, Dordogne.

Acknowledgements: this work was financially supported by the French National Research Agency (Project ANR MADAPCA - Micro-analyses et datations de l'art préhistorique dans son contexte archéologique: directed by P. Paillet). The authors would like thank L. Pichon, B. Moignard for their support during experiments on AGLAE accelerator, and I. Reiche and M. Verez for their participation to the selection of the archaeological artefacts at the Abri Pataud.

Citation: Lebon M, Beck L, Grégoire S, Chiotti L, Nespoulet R, Menu M, Paillet P, 2014. Prehistoric pigment characterisation of the Abri Pataud rockshelter (Dordogne, France). In: RH Tykot (ed.), Proceedings of the $38^{\text {th }}$ International Symposium on Archaeometry - May $10^{\text {th }}-14^{\text {th }} 2010$, Tampa, Florida. Open Journal of Archaeometry 2:5456.

Presented at the $38^{\text {th }}$ International Symposium on Archaeometry - May $10^{\text {th }}-14^{\text {th }} 2010$, Tampa, Florida.

This work is licensed under a Creative Commons Attribution 3.0 License (by-nc 3.0).

(C) Copyright M. Lebon et al., 2014

Licensee PAGEPress, Italy

Open Journal of Archaeometry 2014; 2:5456

doi:10.4081/arc.2014.5456

sis techniques mentioned above, such as micro-PIXE analysis, can be performed directly on samples without any preparation and damages for objects. By using external beam, this technique requires no sampling and was widely used for the characterisation of artwork and archaeological materials. In this study, we propose to apply non-destructive micro-PIXE analysis on prehistoric pigments from the site of Abri Pataud, as well as on raw material and on archaeological artefacts themselves.

The Upper Palaeolithic site of Abri Pataud is located in the town of Les Eyzies (Dordogne, France) and corresponds to a rock-shelter overlooking the Vézère river valley. The collapsed rock-shelter was extensively excavated by H.L. Movious from 1953 to 1964 that revealed the major part of the stratigraphic sequence (Movius, 1977). These excavations have exposed a $c a$. 9-m-thick sequence containing 14 archaeological layers (Figure 1). The stratigraphy recorded periods between 34,000 and 21,000 BP corresponding to Aurignacian, Gravettian and Solutreen human 
occupations. Since 2005, a new program of excavation has been conducted by $R$. Nespoulet and L. Chiotti on the archaeological Layer 2 attributed to the Final Gravettian (2220,000 BP). The Final Gravettian period (also called Protomagdalenian period) constitutes an original and localised archaeological culture only identified in four sites located in the southwest of France (Abri Pataud, Dordogne; Laugerie-Haute, Dordogne Le Blot, HauteLoire; Les Peyrugues, Lot) (Chiotti et al., 2009; Nespoulet et al., 2008).

The different excavations conducted on the occupation Layer 2 have yielded abundant archaeological materials. Among these materials, an exceptional concentration of human remains (more than $300, \mathrm{MNI}=6$; 3 adults and 3 children) were discovered in the rear part of the shelter. These remains constitute the most important human bone material for this period. The status of these human remains is still uncertain, but disturbed primary burials are suspected on the basis of a significant set of particular objects. Worked artefacts have been found in association with these human remains such as ivory beads, a pierced reindeer antler, a herbivore scapula displaying red pigment punctuations, a collected acheulean biface, engraved rocks, etc. (Chiotti et al., 2009). Some raw reddish pigments and faceted ochre blocks have also been found in the Layer 2 and 3 (Figure 2). Understanding the relationship between the human remains and this archaeological assemblage has encouraged a new program of excavation in Layer 2 since 2005 , and the resumption of the study of the archaeological material from previous excavations (Nespoulet et al., 2008).

A part of the materials excavated from Layer 2 testifies for the ancient ornament of the rock-shelter wall. Among the numerous limestone fragments, coming from the natural exfoliation of the rock-shelter walls induced by successive actions of freeze and thaw, and water infiltration in porous limestone, more than 250 of these fragments are covered by reddish pigments. Various questions arise as to the origin of these decorated limestone blocs, and the archaeological data can not yet be used to determine if painting were contemporaneous with the occupation Layer 2 , or if the coloured limestone fragments are some evidences of the alteration of ancient painting made prior to the deposit of this Layer 2 (for example contemporaneous to Layer 3 occupation). In order to contribute to this issue, micro-PIXE analyses were performed to determine the elemental composition of raw pigments from the Layer 2, Layer 3 and the Éboulis 2/3, and their composition was compared to those of the pigments found on coloured limestone fragments and decorated prehistoric objects from the Layer 2.

\section{Materials and Methods}

The samples of the Abri Pataud examined in this study are listed in Table 1. The samples covered or composed by reddish iron pigments were mainly excavated from archaeological Layer 2 and 3.

A selection of 4 decorated fragments of limestone coming from the natural alteration of the rock-shelter walls and found in Layer 2 were analysed (AP1, AP2, AP3, AP4). Two similar samples (AP7 and AP8) coming from a sterile level situated between the archaeological Layer 2 and 3 (Éboulis 2/3) were investigated for comparison. Two artefacts were also included: a pebble covered by red pigment (apparently used as grindstone) discovered in Layer 3 (AP 16), and a scapula of a big herbivorous mammal decorated by more than 70 reddish

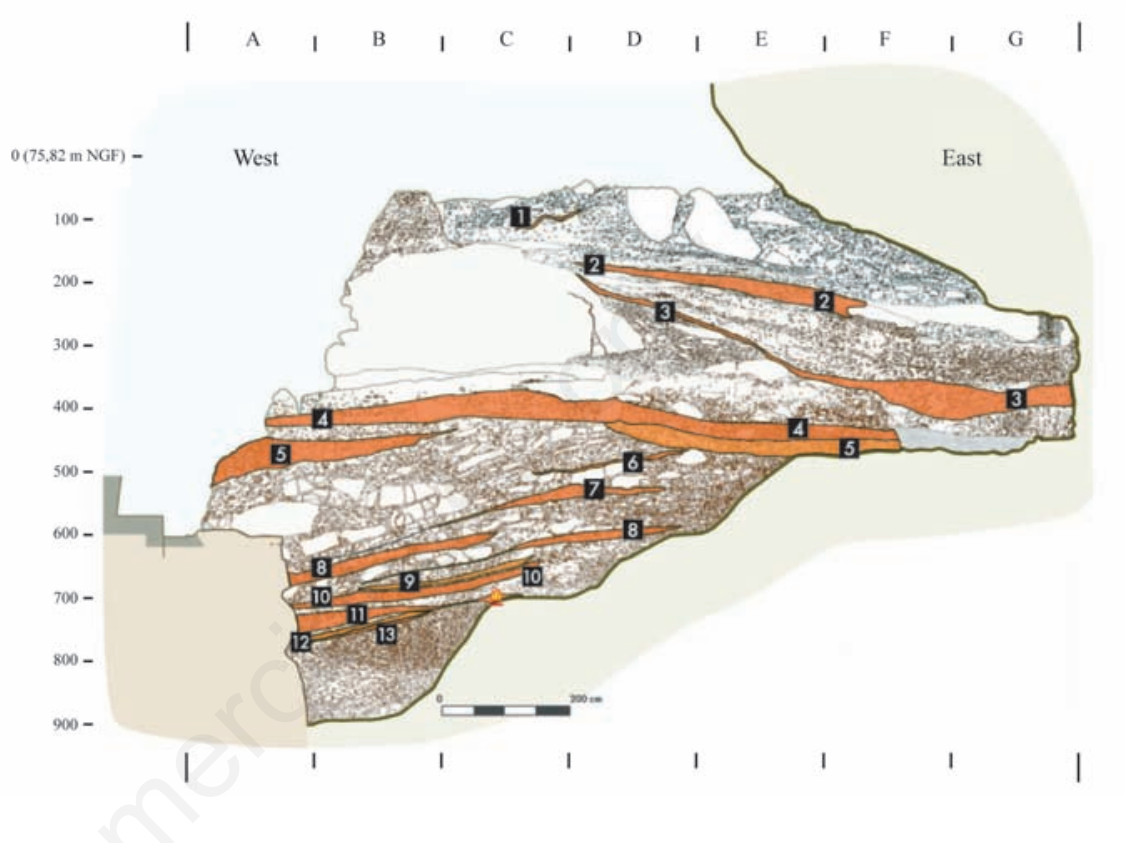

Figure 1. Stratigraphy of the Pataud shelter (Les Eyzies, Dodorgne, France).

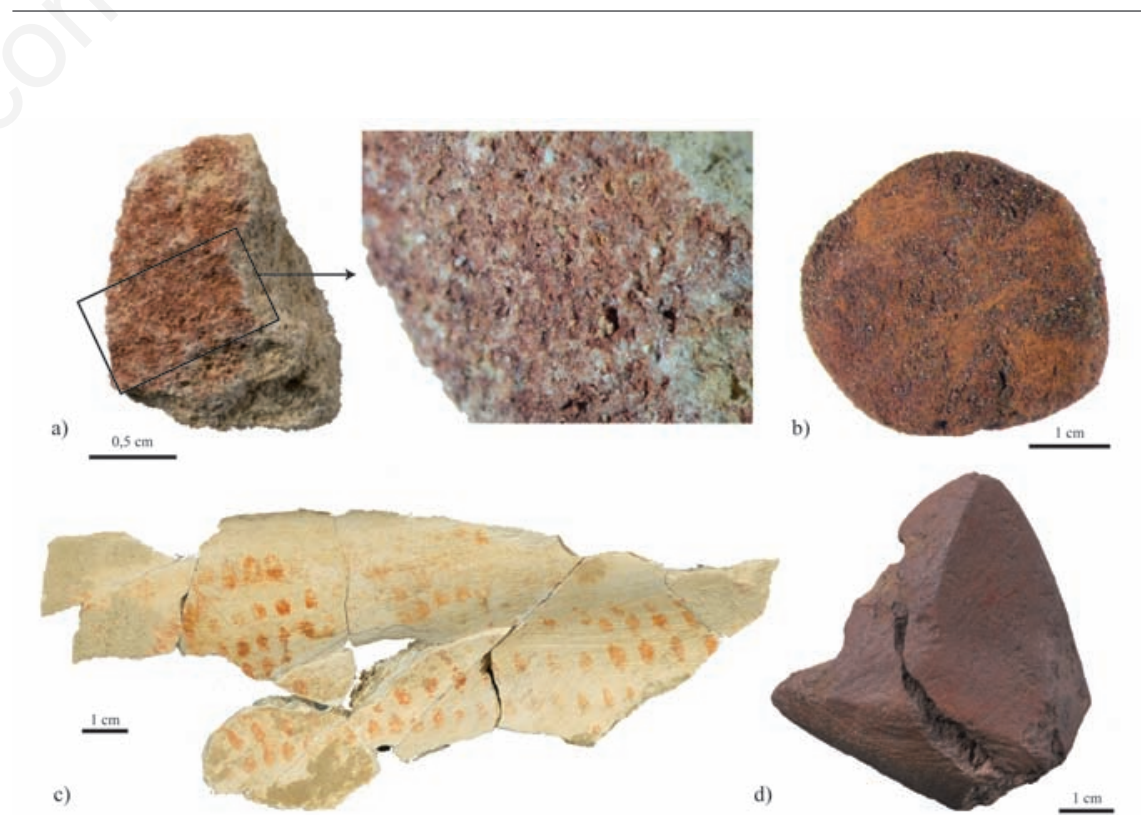

Figure 2. Examples of raw pigments, decorated objects and artefacts from the Abri Pataud; a) decorated limestone block (AP3), b) raw pigment (AP13), c) decorated scapula (Sca), d) faceted ochre block (AP11). 
spots found in Layer 2 (Sca).

The sample set of potential raw materials is composed of 2 fragments of bulk pigment from Layer 2 (samples AP13 and AP15) and 3 ochre artefacts from Layer 3 (AP10, AP11, AP12). These 3 artefacts correspond to angular blocks showing several plate faces marked by striations that testify to their rubbing on an abrasive surface to obtain pigment powder.

\section{Particle induced X-ray emission analysis}

Elemental analysis of the samples was performed by particle induced X-ray emission (PIXE) using the external proton micro-beam of the particle accelerator AGLAE (Calligaro et al., 2004; Salomon et al., 2008), dedicated to the analysis of art and archaeological material (Louvre museum, Paris). Samples were placed without any specific preparation in front of the $3 \mathrm{MeV}$ proton beam focused at the surface of the sample ( $c a .40 \mu \mathrm{m}$ in diameter). Surface areas free of sediments or others impurities were selected for analysis, and scanned by the micro-beam in order to homogenise elemental concentrations. Low and high energy X-ray emissions were detected using two $\mathrm{Si}(\mathrm{Li})$ detectors placed symmetrically at $45^{\circ}$ from the incident proton beam. Spectrum evaluation and quantification of the sample elemental composition were performed using the GUPIX software (Maxwell et al., 1988). The experimental conditions provide detection limits ranging from 100 to $1000 \mathrm{ppm}$ for light and medium elements (Na to $\mathrm{Fe}$ ) and from 5 to 20 ppm for heavy trace elements (Cu to $\mathrm{Sb})$.

\section{Results and Discussion}

The iron concentrations measured for the selected samples vary between 1.3 and $82.3 \%$. This wide range of $\mathrm{Fe}$ concentration can be related to different geological provenances and to the mineralogical composition of iron rich pigments, generally composed by a mixture of iron minerals and other associated minerals including clays or quartz. The variation of the concentration of $\mathrm{Al}$ and $\mathrm{Si}$ (respectively in the range of $0.5-32.3 \%$, and $2.7-67 \%$ ) confirm the important part of these additional minerals for certain samples. The variation of Fe concentration between samples can also be caused by differences in the substrates supporting the pigment layer or by variations of the pigment layer thickness.

In order to determine which elements can be used as specific fingerprints of the iron mineral phase composition, the correlation between Fe content and other element contents was tested. The elements showing a significant positive correlation between their concentrations and $\mathrm{Fe}$ concentration were selected for analysis and all other elements were discarded. It was assumed that the elements correlated to Fe concentration constitute a part of iron oxide phase whereas elements negatively correlated or not linked with Fe content were considered to be associated with other minerals composing surrounding sediment, associated minerals, or the painting substrate.

Different minor and trace elements were found to be positively correlated to Fe content and thus associated to the iron mineral phase: $\mathrm{Mn}, \mathrm{As}, \mathrm{Zn}$ and to a lesser extent Co. The relationship between Fe and these elements is plotted in Figure 3 for samples AP1, AP2, AP3 and AP4. Some other elements were also positively correlated to Fe for specific samples, more particularly V $\left(\mathrm{r}^{2}=0.95\right)$ and $\mathrm{Mg}\left(\mathrm{r}^{2}=0.74\right)$ for samples AP11 and 12 respectively (Figure 4).

In order to limit the influence of Fe content variations between samples, the $\mathrm{Mn}, \mathrm{As}, \mathrm{Zn}$, $\mathrm{Co}$ and $\mathrm{V}$ contents were ratioed to Fe concentration. These element ratios were then compared using bivariate plots to determine which
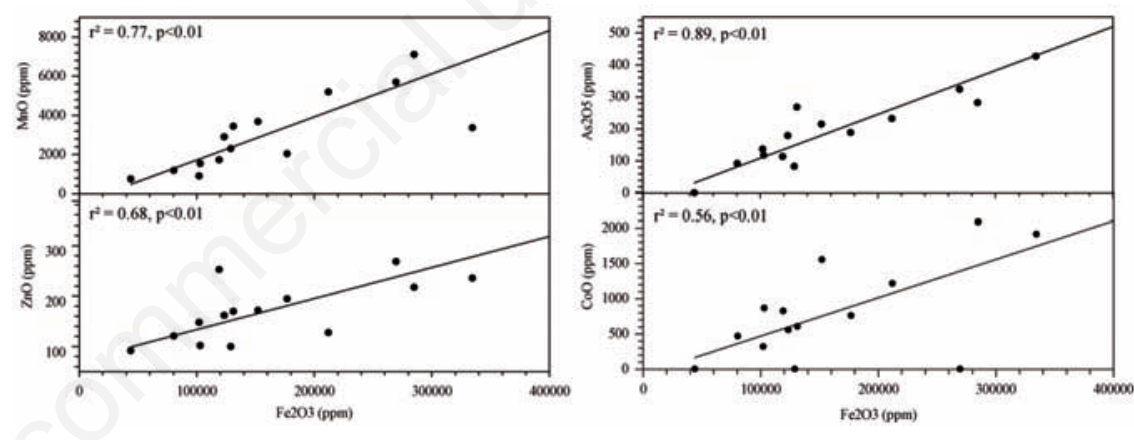

Figure 3. Concentration of $\mathrm{Mn}, \mathrm{Zn}$, As, and Co oxides (ppm) as a function of iron oxide concentration for decorated blocks from Layer 2 (AP1, AP2, AP3, AP4).

Table 1. List of the selected samples analysed by micro-particle-induced X-ray emission.

\begin{tabular}{|c|c|c|c|c|c|}
\hline Sample & Layer & Type & Substrate & Number of points & Inventory number \\
\hline AP1 & Layer 2 & Decorated rock & Limestone & 5 & U76C-55 \\
\hline AP2 & Layer 2 & Decorated rock & Limestone & 3 & U76B-39 \\
\hline AP3 & Layer 2 & Decorated rock & Limestone & 4 & U76C-92 \\
\hline AP4 & Layer 2 & Decorated rock & Limestone & 3 & V76C-200 \\
\hline AP13 & Layer 2 & Decorated rock & Limestone & 2 & 36951 \\
\hline AP15 & Layer 2 & Raw pigment & - & 3 & 36962 \\
\hline Sc & Layer 2 & Decorated bone & Bone & 5 & \\
\hline AP7 & Layer $2 / 3$ & Decorated rock & Limestone & 3 & AP-EC-88 \\
\hline AP8 & Layer 2/3 & Decorated rock & Limestone & 2 & AP-EC-86 \\
\hline AP10 & Layer 3 & Faceted ochre blocks & - & 1 & $3-1140$ \\
\hline AP11 & Layer 3 & Faceted ochre blocks & - & 5 & 1459 \\
\hline AP12 & Layer 3 & Faceted ochre blocks & - & 3 & $3-1138$ \\
\hline AP16 & Layer 3 & Grindstone & Granite & 8 & - \\
\hline
\end{tabular}


samples can be grouped on the basis of their composition. The Figure 5 displays the biplots obtained comparing $\mathrm{Mn} / \mathrm{Fe}$ ratio to $\mathrm{As} / \mathrm{Fe}$, $\mathrm{Zn} / \mathrm{Fe}, \mathrm{Co} / \mathrm{Fe}$ and $\mathrm{V} / \mathrm{Fe}$ ratios. These results demonstrate that these different element ratios can be used to discriminate several groups of pigments.

The composition of pigments covering the decorated blocks from the layer 2 (AP1, AP2, AP3 and AP4) is relatively homogeneous and differs from the composition of the samples coming from the Éboulis 2/3 (AP7 and AP8). This difference is mainly due to the $\mathrm{Mn} / \mathrm{Fe}$ ratio values and to the absence of $\mathrm{V}$ in samples AP7 and AP8. It suggests that the decorated blocks discovered in Layer 2 and in the Éboulis $2 / 3$ are covered by distinct pigments.

The AP16 sample presents higher $\mathrm{Mn} / \mathrm{Fe}$ ratios than the previous samples and its composition is distinct from the other groups.

The composition of the pigment covering the scapula fragment is similar to the composition of the decorated blocks from the Layer 2, except for Zn contents that are higher than for the samples AP1-4. This difference can be explained by the higher Zn content measured in this fossil bone substrate (190 to $350 \mathrm{ppm}$ ) than in the limestone substrate (generally under limit of detection). The origin of the pigment covering the scapula and the wall fragments could thus be similar, but the pigment layer thickness and the penetration depth of the incident proton beam in the bone substrate $(\approx 100 \mu \mathrm{m})$ limit the possibility to definitely determine the correspondence between the two pigments.

The raw material discovered in archaeological Layer 2 and 3 were also analysed and their composition was compared to those of the pigments covering the decorated limestone blocks and the scapula from the archaeological Layer 2. The composition of the sample AP13 clearly differs from those of the pigments covering the decorated archaeological objects since no trace of manganese was detected for this raw material sample.

The samples AP10, AP11 and AP12 present lower ratio values than the others analysed pigments. Although these artefacts exhibit some evidences of their use to obtain pigment powder, their composition differ from the decorated blocks and objects found in archaeological Layer 2. On the contrary, the elemental composition of the raw material AP15 is more consistent with the composition of the pigment used during Layer 2 occupation as demonstrated by the Figure 5 . This chemical concordance could indicate the use of the raw material AP15, or at least material coming from the same geological origin, as source of pigment for rock painting during the Final Gravettian occupation at the Abri Pataud. At the stage of our investigations carried out on a limited number of samples, it seems that the

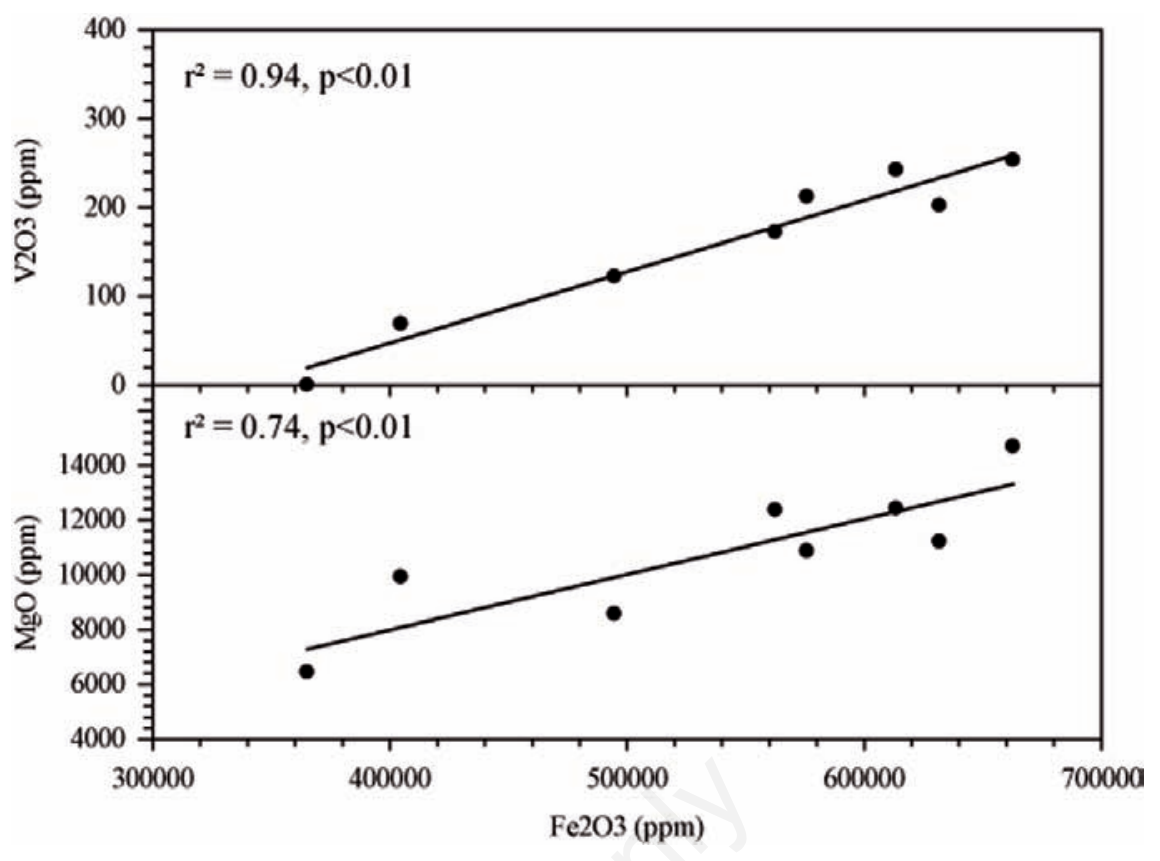

Figure 4. Concentration of $\mathrm{V}$ and $\mathrm{Mg}$ oxides (ppm) as a function of iron oxide concentration for samples AP11 and AP12.
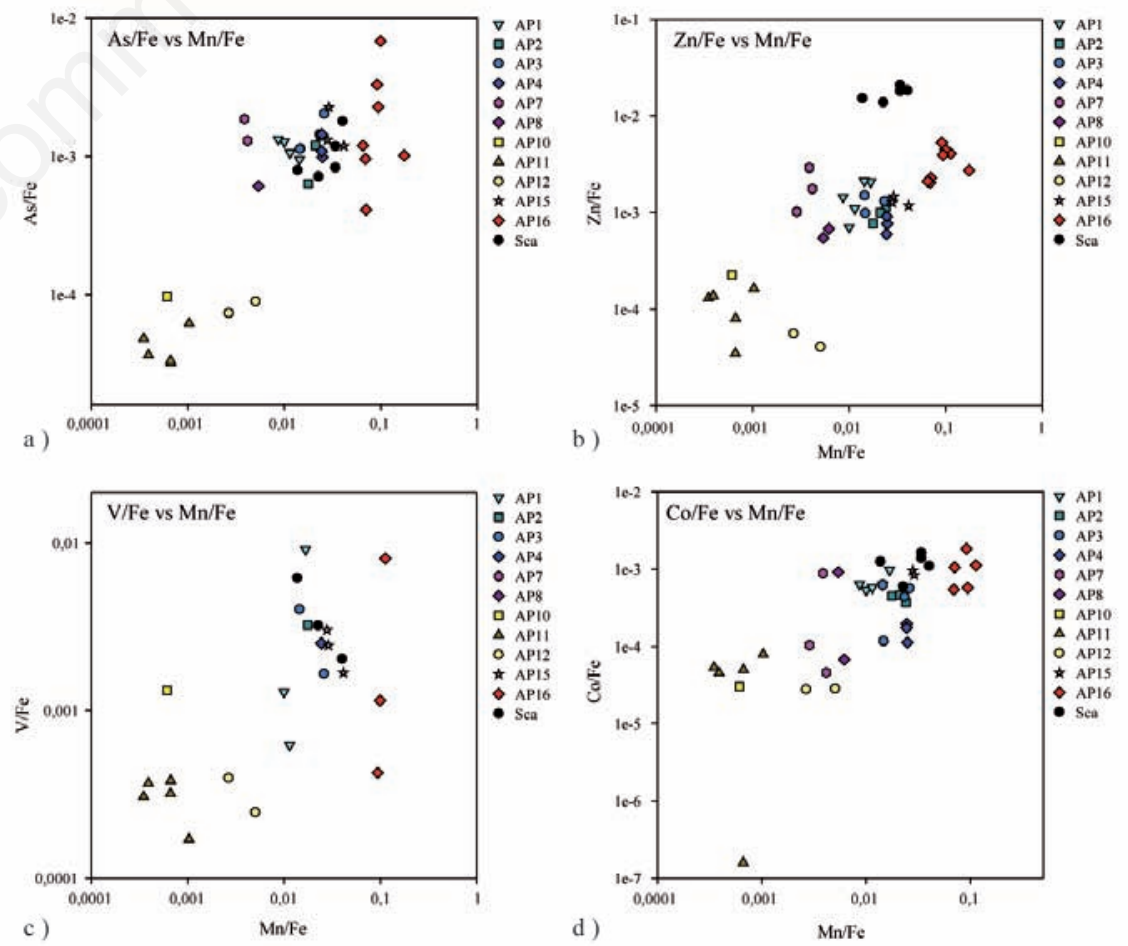

Figure 5. Bivariate plots of a) $\mathrm{As} / \mathrm{Fe}, \mathrm{b}) \mathrm{Zn} / \mathrm{Fe}, \mathrm{c}$ ) $\mathrm{V} / \mathrm{Fe}$, and d) $\mathrm{Co} / \mathrm{Fe}$ ratios compared to $\mathrm{Mn} / \mathrm{Fe}$ ratio in the pigments of the Abri Pataud analysed by PIXE. The sample AP13, which does not contain any Mn, was not plotted on these graphs. 
composition of raw material found in Layer 2 is similar to the composition of pigments covering the decorated blocks fallen from the wall found in the same layer, whereas the composition of the raw pigments from the Layer 3 is significantly different. This suggests that the shelter was decorated during the Final Gravettian occupation and that the degradation of the wall started contemporaneously to the deposit of archaeological Layer 2 .

\section{Conclusions}

Different studies have demonstrated that the elemental composition of ochre and iron based pigments can be used to discriminate different geological provenances. In this paper, we have applied elemental PIXE analysis to archaeological material in order to compare pigments covering different substrates and found in different archaeological layers.

The micro-PIXE spectroscopy constitutes an analytical technique routinely used for the characterisation of archaeological and artwork material. This technique enabled performing elemental analysis without any damages for valuable archaeological materials. The ability to focus the ion beam on a small area $(\approx 40 \mu \mathrm{m}$ in diameter) allowed performing localised analyses on ochre residues applied on artefact or on fragment of the rock-shelter wall, and to choose some part of the sample without sediments deposits that could have limited the ability to identify iron phase fingerprints.

Through the selection of elements associated exclusively to the iron mineral phase, it was possible to identify different groups of pigments showing similar composition. The results demonstrate that the pigments covering the decorated fragments of the limestone wall found during the excavation of Layer 2 have a homogeneous elemental composition. These pigments seem to have the same origin as a raw pigment fragment found in the same layer, whereas their composition differs from those of the pigments found in previous occupation layer (Layer 3). This suggests that the shelter was decorated during the Final Gravettian occupation, information that the archaeological data had not allowed to determine up to now. These new data thus provide new insights for the improvement of the understanding of the archaeological context, and the status of the artefacts and the human remains discovered in this layer.

\section{References}

Beck L, Lebon M, Pichon L, Menu M, Chiotti L,
Nespoulet R, Paillet P, 2011. PIXE characterisation of prehistoric pigments from Abri Pataud (Dordogne, France). X-Ray Spectrom 40:219-23.

Bikiaris D, Daniilia S, Sotiropoulou S, Katsimbiri 0, Pavlidou E, Moutsatsou AP, Chryssoulakis Y, 2000. Spectrochim Acta A 56:3-18.

Calligaro T, Dran JC, Salomon J, Walter P, 2004. Review of accelerator gadgets for art and archaeology. Nucl Instr Meth Phys Res B 226:9-37.

Chalmin E, Menu M, Pomiès M-P, Vignaud C, Aujoulat N, Geneste J-M, 2004. [Les blasons de Lascaux]. [Article in French]. L'Anthropologie 108:571-92.

Chiotti L, Nespoulet R, Henry-Gambier D, Morala $\mathrm{A}$, Vercoutère C, Agsous S, Lenoble A, Marquer L, Grimaud-Hervé D, 2009. [Statut des objets « extra-ordinaires » du Gravettien final de l'abri Pataud (Les Eyzies, Dordogne) : objets abandonnés dans l'habitat ou dépôt intentionnel?]. In: Bonnardin S, Hamon C, Lauwers M, Quilliec B, (eds.), [XXIXe Rencontres Internationales d'Archeologie et d'Histoire d'Antibes]. [Book in French]. APDCA Press, Antibes, France, pp. 306-22.

Clottes J, Menu M, Walter P, 1990. [La préparation des peintures Magdaléniennes des cavernes Ariègoise]. [Article in French]. Bull Soc Préhist Fr 87:170-92.

Darchuk L, Tsybrii Z, Worobiec A, Vázquez C, Palacios 0M, Stefaniak EA, Gatto Rotondo G, Sizov F, Van Grieken R, 2010. Argentinean prehistoric pigments' study by combined SEM/EDX and molecular spectroscopy. Spectrochim Acta A 75:1398-402.

D'Errico S, Salomon H, Vignaud C, Stringer C, 2010. Pigments from the Middle Palaeolithic levels of Es-Skhul (Mount Carmel, Israel). J Archaeol Sci 37:3099-110.

Erlandson JM, Robertson J, Descantes C, 1999. Geochemical analysis of eight red ochres from Western North America Am Antiquity 64:517-26.

Green RL, Watling RJ, 2007. Trace element fingerprinting of Australian ocher using laser ablation inductively coupled plasma-mass spectrometry (LA-ICP-MS) for the provenance establishment and authentication of indigenous art. J Forensic Sci 52:851-9.

Lombard M, 2007. The gripping nature of ochre: the association of ochre with Howiesons Poort adhesives and Later Stone Age mastics from South Africa. J Hum Evol 53:406-19.

Mariotti V, Bonfiglioli B, Facchini F, Condemi S, Belcastro MG, 2009. Funerary practices of the Iberomaurusian population of Taforalt (Tafoughalt) (Morocco, 11-12000 BP): new hypotheses based on a grave by grave skeletal inventory and evidence of deliberate human modification of the remains. J Hum Evol 56:340-54.
Maxwell JA, Campbell JL, Teesdale WJ, 1988. The Guelph PIXE software: a description of the code package. Nucl Instr Meth Phys Res B 43:218-30.

Menu M, 2009. [L'analyse de l'art prehistorique]. [Article in French]. L'Anthropologie 113:54758.

Movius HL, 1977. Escavation of the Abri Pataud, Les Eyzies (Dordogne). American School of Prehistory Research, Peabody Museum, Harvard University ed., Cambridge, MA, USA.

Nel P, Lynch PA, Laird JS, Casey HM, Goodall LJ, Ryan CJ, Sloggett RJ, 2010. Elemental and mineralogical study of earth-based pigments using particle induced X-ray emission and Xray diffraction. Nucl Instr Meth Phys Res A 619:306-10.

Nespoulet R, Chiotti L, Henry-Gambier D, Agsous S, Lenoble A, Morala A, Guillermin P, Vercoutère C, Grimaud-Hervé D, Marquer L, Patou-Mathis M, Pottier C, Vannoorenberghe A, Verez M, 2008. [L'occupation humaine de l'abri Pataud il y a 22000 ans : problématique et résultats préliminaires des fouilles du niveau 2]. In: Jaubert J, Bordes J-G, Ortega I (eds.), [Les sociétés paléolithique dans un Grand Sud-Ouest de la France: nouveaux gisements, nouveaux résultats, nouvelles méthodes]. [Book in French]. Actes des Journées de la Société Préhistorique Française 47:325-34.

Pomiès MP, Menu M, Vignaud C, 1999. TEM observations of goethite dehydration: application to archaeological samples. J Eur Ceram Soc 19:1605-14.

Popelka-Filcoff R, Robertson J, Glascock M, Descantes C, 2007. Trace element characterization of ochre from geological sources. $\mathrm{J}$ Radioanal Nucl Ch 272:17-27.

Ramos PM, Ruisánchez I, Andrikopoulos KS, 2008. Micro-Raman and X-ray fluorescence spectroscopy data fusion for the classification of ochre pigments. Talanta 75:926-36.

Salomon J, Dran JC, Guillou T, Moignard B, Pichon L, Walter P, Mathis F, 2008. Present and future role of ion beam analysis in the study of cultural heritage materials: The example of the AGLAE facility. Nucl Instr Meth Phys Res B 266:2273-8.

Smith DC, Bouchard M, Lorblanchet M, 1999. An initial Raman microscopic investigation of prehistoric rock art in caves of the Quercy district, S.W. France. J Raman Spectrosc 30:347-54.

Vignaud C, Salomon H, Chalmin E, Geneste J-M, Menu M, 2006. [Le groupe des 'bisons adossés' de Lascaux. Étude de la technique de l'artiste par analyse des pigments]. [Article in French]. L'Anthropologie 110:482-99. 